\title{
Announcement
}

\section{European Journal for Crime, Criminal Law and Criminal Justice Young Scholar Competition}

The European Journal for Crime, Criminal Law and Criminal Justice is pleased to announce that it will once again hold a Young Scholars Competition. Submitted articles may cover any topic that falls within the broad spectrum of the aims and scope of the Journal (http://www.brill.com/european-journal-crimecriminal-law-and-criminal-justice). Up to a maximum of four winners will be chosen by a jury and the successful authors will be invited to present their papers at a conference in 2021 at the University of Leiden.

For the purposes of this competition, young scholars are those who have not yet reached the age of 35 at the deadline for submission on June 12020. The European Journal for Crime, Criminal Law and Criminal Justice will cover the travel and accommodation costs for the winners to participate in the conference. When submitting an article for the competition, please send an additional email to Christopher Murphy (eccleditor@outlook.com), the Journal's Managing Editor, notifying him of your intention to participate. 
